The Almanac man

\section{Jack Meadows}

Nevll Maskelyne: The Seaman's Astronomer. By Derek Howse. Cambridge University Press: 1989. Pp. 280. £40, $\$ 59.50$.

THE Royal Observatory at Greenwich played a central role in British astronomy for three centuries. Yet there are few modern biographies of the Astronomers Royal, those king-pins of the astronomical establishment. This may be because the kind of work that traditionally occupied much of their time - positional astronomy - has had a rather poor press over the past few decades. One of the marvellous quotes in Derek Howse's book comes from an Assistant at the Observatory in the eighteenth century:

Nothing can exceed the tediousness and ennui of the life the assistant leads in this place, excluded from all society. . . Here forlorn, he spends days, weeks, and months, in the same long wearisome computations ... He is also up frequently three or four times in the night.

These bitter comments reflect only too well the image that a modern astrophysi-

\section{IMAGE UNAVAILABLE FOR COPYRIGHT REASONS}

Nevil Maskelyne (1732 - 1811).

cist has of the olden days. This new biography of the fifth Astronomer Royal, Nevil Maskelyne, shows that both he, and most of his assistants, had much more interesting lives. One reason was that astronomy in the eighteenth century had a greater strategic significance than it has today. As the book's subtitle indicates, astronomers were the chief advisors to governments on how to navigate accurately at sea - a limiting factor for all long voyages at that time. Although the Royal Observatory had been set up by Charles II primarily to find a means of determining longitude at sea, that aim had still not been achieved by the mid-eighteenth century. Maskelyne's historical importance was that two practical navigational techniques were developed during his period in office. His own contribution was the development of an almanac which allowed position at sea to be determined from the position of the Moon in the sky. This Nautical Almanac was an essential item for ocean-going ships until after the Second World War.

As befitted his post, Maskelyne had some involvement in most of the principal astronomical advances in the latter half of the eighteenth century. His best-known work was his measurements of Schiehallion, a mountain in Perthshire, which he used as a means of estimating the density of the Earth. As Howse says, the analysis may have involved the earliest application of contour lines (although the French might dispute this). In another chapter, we are given the full story of Maskelyne's uncomprehending discovery of the personal equation. Similar fascinating details occur throughout the book - for example, Maskelyne's dealings with Captain Cook, Sir Joseph Banks and assorted quarrelsome clockmakers, or how Mason and Dixon came together to measure their line in the United States.

This is as good a scientific biography as one could wish to have - fully documented, well illustrated, yet written throughout with a light touch. It provides an excellent insight into the world of British astronomy some two centuries ago

Jack Meadows is in the Department of Library and Information Studies, Loughborough University, Loughborough LE11 3TU, UK.

\section{The good bits}

\section{William H. Press}

The Turing Omnibus: 61 Excursions in Computer Science. By A.K. Dewdney. Computer Science Press: 1989. Pp. 415. Distributed by W.H. Freeman, \$24.95, £22.95.

WE at universities like to have some idea - if only of the vaguest sort - of what our colleagues in other departments actually do. Most of us have a faint glimmering of what biochemistry, say, is about, or sociology, or Sanskrit or statistics. But what of that brash new department, computer science?

A seemingly benign computer scientist was on one occasion approached at an interdisciplinary, and well-lubricated, academic function. "Just as physics studies reality", he declared, "computer science studies artificial reality". Somehow this is not the kind of explanation one is looking for.

Now comes A.K. Dewdney, a computer scientist at the University of Western Ontario, with just the kind of answers that we need. The Turing Omnibus is full of wit - both kinds - from the double-barrelled pun of its title, all the way through its 61 short chapters, each of which amounts to a short essay, five or six pages long, on a particular topic in computer science. The "good bits" of computer science, Professor Dewdney cannot resist calling them.

This is a light-hearted but by no means light-weight volume - a book that 'does' Gödel's theorem in seven pages is no easy read. Although there are few mathematical proofs as such, there are a lot of summaries of the essential arguments of important proofs, algorithms and constructions. Thus we have wonderfully concise discussions of language hierarchies (regular versus context-free and so on), error-correcting codes, NP-completeness, tomographic algorithms, hashing, linear programming, minimum spanning trees, the knapsack problem, lambda calculus, neural nets - plus (literally) hundreds of additional concepts, because several ideas are frequently covered in a single short chapter. The "good bits", indeed! There is a detailed index. If its prose style had been turgid instead of informal, its visual design scholastic instead of amiable, The Turing Omnibus could have called itself Short Encyclopaedia of Computer Science and it would have elicited generally warm reviews.

Against this praiseworthy background one must, however, mention a serious deficiency: technical accuracy, or 'factchecking', of the book is not up to the standard of a credible short encyclopaedia, or a first-rate textbook. For example, the discussion of probabilistic tests for primality, while it gets the spirit of the idea right, states the algorithm incorrectly. Another example: the account of cubic splines seems to miss the point that they are smooth in their second derivative, and that they are global, not local.

These kinds of slips - there are some others - make The Turing Omnibus much less useful than it might otherwise have been; researchers in related fields, or students, would be ill-advised to rely on it as a one-volume reference work (as the author suggests in his preface). Such a caveat in no way diminishes its charm and usefulness in a limited niche, however. It is nearly the perfect book for noncomputer scientists who want to learn something about the field, for undergraduates who want a detailed snapshot of what their prospective major field is about, or even for the bright secondary school student whose imagination will be fired up by a book that shows that there can be diverse, deep ideas inside computers - and no small amount of challenging intellectual fun.

William H. Press is in the Center for Astrophysics, Harvard University, 60 Garden Street, Cambridge, Massachusetts 02138, USA. 